\title{
Endovascular selective hypothermia facilitates giant aneurysm clipping: illustrative case
}

\author{
Thomas K. Mattingly, MD, ${ }^{1,5}$ Pablo Lopez-Ojeda, MD, ${ }^{1}$ Miguel Arango, MD, ${ }^{2}$ Chris Harle, MD, ${ }^{2}$ Nirmal Kakani, MD, ${ }^{3}$ Peter Allen, RN, \\ Barbara Lehrbass, RT, ${ }^{3}$ and Stephen P. Lownie, MD ${ }^{1,3}$
}

Departments of ${ }^{1}$ Neurosurgery, ${ }^{2}$ Anesthesiology, ${ }^{3}$ Imaging Sciences, and ${ }^{4}$ Cardiac Surgery, Western University, London, Ontario, Canada; and ${ }^{5}$ Department of Neurosurgery, University of Rochester, Rochester, New York

\begin{abstract}
BACKGROUND The authors present a case of selective hypothermia used for neuroprotection during clipping of a giant partially thrombosed middle cerebral artery (MCA) aneurysm. Although these cases have traditionally required deep hypothermic cardiac arrest, this case illustrates a novel and entirely endovascular solution that avoids cardiac standstill and whole-body cooling.

OBSERVATIONS This is, to the authors' knowledge, the first case in human surgery of a catheter-based selective hypothermic circuit used to facilitate MCA trapping for almost 30 minutes. Core temperatures never dropped below $34^{\circ} \mathrm{C}$, and the patient recovered uneventfully and has been well for over 5 years.
\end{abstract}

LESSONS The technical nuances and physiological changes unique to selective hypothermia are discussed.

https://thejns.org/doi/abs/10.3171/CASE2090

KEYWORDS hypothermia; giant aneurysm; endovascular

Hypothermia remains the best-studied neuroprotectant. One use for hypothermia is to facilitate circulatory arrest during aneurysm reconstruction. ${ }^{1}$ In giant partially thrombosed aneurysms, a prolonged temporary occlusion is required to evacuate the thrombus and reconstruct the neck. Hypothermia in combination with circulatory arrest allows for softening of the lesion, safe entry into the aneurysm fundus for evacuation of the thrombus, and operation within a bloodless field. ${ }^{2,3}$ However, morbidity associated with this approach is well known and includes coagulopathy intraoperatively and postoperative complications such as myocardial infarction, sepsis, and pneumonia. ${ }^{4,5}$

In 2004, aneurysm clipping via selective brain hypothermia was first described. ${ }^{6}$ This approach used direct cannulation of the surgically exposed femoral and carotid arteries to produce a hypothermic bypass. This technique was used successfully to clip a 4.5-cm-diameter, partially thrombosed middle cerebral artery (MCA) aneurysm. Subsequently, in a novel swine model, endovascular selective hypothermia using a percutaneous catheter system (TwinFlo, Thermopeutix, Inc.) was performed, with evidence of significant neuroprotection in the setting of prolonged focal ischemia with cooling during reperfusion. ${ }^{7}$ We describe the first human use of a selective cooling catheter for percutaneous endovascular selective brain cooling, which was used to facilitate clipping of a giant partially thrombosed right MCA aneurysm.

\section{Illustrative Case \\ Clinical Presentation}

A 59-year-old right-handed hypertensive male smoker presented with a 2-day history of right-sided headaches. Magnetic resonance imaging (MRI) disclosed a 2.5-cm-diameter partially thrombosed aneurysm (Fig. 1). The finding of a lumbar puncture was negative for hemorrhage. Angiography demonstrated a giant right MCA aneurysm incorporating the superior M2 branch. The aneurysmal lumen measured $19 \mathrm{~mm} \times 11 \mathrm{~mm}$ with a $7-\mathrm{mm}$ neck. It was believed that the aneurysm could be reconstructed with clips after evacuation of the thrombus. A second option would be an extracranial-intracranial bypass with proximal M1 occlusion.

\section{Perioperative Management}

General endotracheal anesthesia was induced using remifentanil and propofol and was maintained with remifentanil and rocuronium. $A$ transesophageal echocardiography probe was placed. A 6-Fr arterial

ABBREVIATIONS ACT = activated clotting time; $\mathrm{CCA}=$ common carotid artery; IFL = inner flow lumen; $\mathrm{MCA}=$ middle cerebral artery; $\mathrm{MRI}=$ magnetic resonance imaging; $\mathrm{OFL}=$ outer flow lumen.

INCLUDE WHEN CITING Published February 15, 2021; DOI: 10.3171/CASE2090.

SUBMITTED October 27, 2020. ACCEPTED December 7, 2020.

(c) 2021 The authors, CC BY-NC-ND 4.0 (http://creativecommons.org/licenses/by-nc-nd/4.0/). 


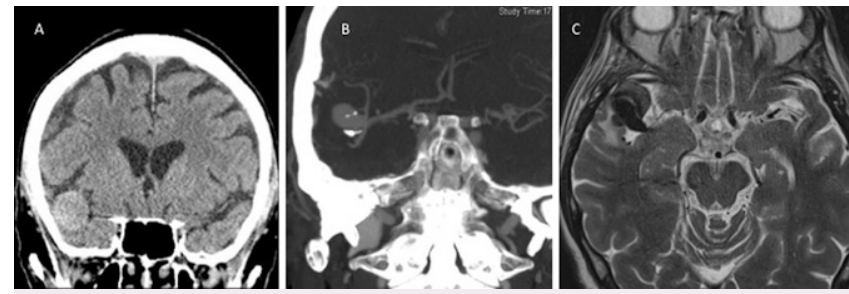

FIG. 1. Preoperative images demonstrating a hyperdense mass in the right sylvian fissure $(A)$, confirmed to be a partially filling lumen with a partially calcified neck (B), and evidence of extensive thrombus (C).

sheath was placed in the right femoral artery for later transcatheter access. A central venous catheter was placed, and hemodynamics were monitored using the FloTrac system (Edwards Lifesciences). Core temperature was measured using esophageal and bladder probes. Warming blankets both below and above the patient minimized temperature fluctuations.

\section{Neurosurgical Technique}

After application of a radiolucent Mayfield clamp in a Zeego Hybrid OR (Siemens), a standard right frontotemporal craniotomy was performed, taking care to preserve the posterior branch of the superficial temporal artery in case it was required for bypass. Intracranial temperature monitoring was performed using a single metallic probe in the subdural space posterior to the craniotomy and a probe in the temporalis muscle. The sylvian fissure was opened under the operating microscope, and large sylvian veins were mobilized toward the temporal lobe. With retraction on the frontal lobe, the aneurysm was mobilized out of the temporal lobe to expose both M2 branches and the parent M1 branch.

\section{Endovascular Perfusion}

With the aneurysm exposure complete, the coaxial catheter system (TwinFlo, Thermopeutix, Inc.) and the cold cardioplegia perfusion system were assembled. The TwinFlo system consists of an $80-\mathrm{cm}, 14-$ Fr outer sheath (outer flow lumen [OFL]) placed in the descending aorta and a 115-cm, 9.5-Fr balloon catheter (inner flow lumen [IFL]) coaxially placed through the outer sheath and guided into the common carotid artery (CCA). The 6-Fr sheath was exchanged for the $14-\mathrm{Fr}, 80-\mathrm{cm}$ TwinFlo outer lumen over a 0.035 -inch exchange length J-tipped wire (Terumo) advanced to the thoracic descending aorta. An initial bolus of $5000 \mathrm{U}$ of heparin was administered. A $5-\mathrm{Fr} \mathrm{H} 1 \mathrm{H}$ catheter was then advanced through the TwinFlo OFL into the distal right CCA. The 5-Fr $\mathrm{H} 1 \mathrm{H}$ catheter was then exchanged for the TwinFlo inner catheter over the 0.035 -inch, $300-\mathrm{cm}$ wire positioned in the distal CCA. A second bolus of $5000 \mathrm{U}$ of heparin was administered to achieve an activated clotting time (ACT) of 300-350 seconds. The inner and outer lumens of the TwinFlo were then attached to the extracorporeal circuit and purged of air, and the position of the IFL was confirmed with hand injection angiography.

\section{Selective Brain Cooling}

Cold blood perfusion was initiated at an inflow temperature of $25^{\circ} \mathrm{C}$ and rate of $240 \mathrm{~mL} / \mathrm{min}$. The inner balloon catheter was inflated to CCA occlusion after 5 minutes of flow, and a gradual reduction in inflow temperature by $5^{\circ} \mathrm{C}$ increments was undertaken until the inflow temperature via the inner catheter was $5^{\circ} \mathrm{C}$. There was a gentle drop in subdural temperature. The temporalis temperature dropped rapidly, although it was already below $30^{\circ} \mathrm{C}$ at baseline. The subdural temperature probe served as a surrogate for brain temperature. Baseline esophageal temperature and bladder temperature decreased from $37.9^{\circ} \mathrm{C}$ and $38.1^{\circ} \mathrm{C}$ to $36.3^{\circ} \mathrm{C}$ and $36.7^{\circ} \mathrm{C}$, respectively, during temporary trapping and definitive clipping of the aneurysm, whereas the brain temperature nadir was $26.6^{\circ} \mathrm{C}$ (Fig. 2). The baseline ACT was 193 seconds. After the initial $10,000 \mathrm{U}$ of heparin, the ACT was 588 seconds.

Once the temperature reached $26.5^{\circ} \mathrm{C}$, the aneurysm sac was opened, and the thrombus was removed with a cavitron ultrasonic aspirator (Integra) until the filling lumen was encountered. The aneurysm was then trapped with the M1 branch and both M2 branches were temporarily clipped. At this point, the ACT was 204 seconds, and an additional $5000 \mathrm{U}$ of heparin was administered. The remainder of the thrombus was evacuated. A large, disc-shaped fragment of calcium was encountered at the level of the neck. The remainder of the neck was fibrous in consistency. Initial clipping consisted of a Drake Sugita fenestrated clip encircling the calcific portion with the distal clip blades closing the aneurysm sac well. A second right-angle Sugita clip was placed between the calcium and the origin of the inferior M2 branch. During aneurysm clipping, the ACT was 248 seconds, and an additional $5000 \mathrm{U}$ of heparin was administered. Temporary clips were removed, followed by deflation of the IFL balloon. A Doppler probe and indocyanine green angiography confirmed the patency of both M2 branches. Intraoperative post-clip angiography was performed through the IFL balloon catheter. This demonstrated complete clipping with a tiny neck remnant. The patient was allowed to rewarm passively. The total selective perfusion time was 2 hours and 4 minutes, and the aneurysm trapping time was 29 minutes.

\section{Closure}

The IFL was clamped off from the perfusion circuit and removed, leaving the OFL in the descending aorta until the craniotomy was closed. During closure, the ACT was 269 seconds, and, although the subdural space was dry, the epidural space was oozy. Heparin was reversed with a half dose of protamine $50 \mathrm{mg}$, which slowed epidural bleeding significantly and brought the ACT to 181 seconds, just below baseline. Closure of the craniotomy was uneventful. The 14-Fr femoral puncture site was sealed with 2 closure devices (Perclose Proglide devices, Abbott).

\section{Postoperative Course}

The patient was alert and following commands for all 4 extremities within several hours of surgery. He was discharged to home without deficit on postoperative day 5 . Follow-up MRI studies demonstrated no change in the region of surgery. Five years postoperatively, he remains neurologically intact, with a limp due to severe knee osteoarthritis.

\section{Discussion}

Selective Hypothermia for Neuroprotection in Focal Ischemia

Whole-body hypothermia for neuroprotection during treatment of cerebral aneurysms has been used since the 1950s. This was initially combined with circulatory arrest to provide a bloodless field with aneurysm softening. ${ }^{8}$ Several series of deep hypothermia circulatory arrest have been published, but its use has remained infrequent because of complexity, morbidity, and development of alternative techniques (endovascular, adenosine). ${ }^{3-5,9}$ Selective hypothermia, a more efficient way of delivering hypothermia without the systemic 


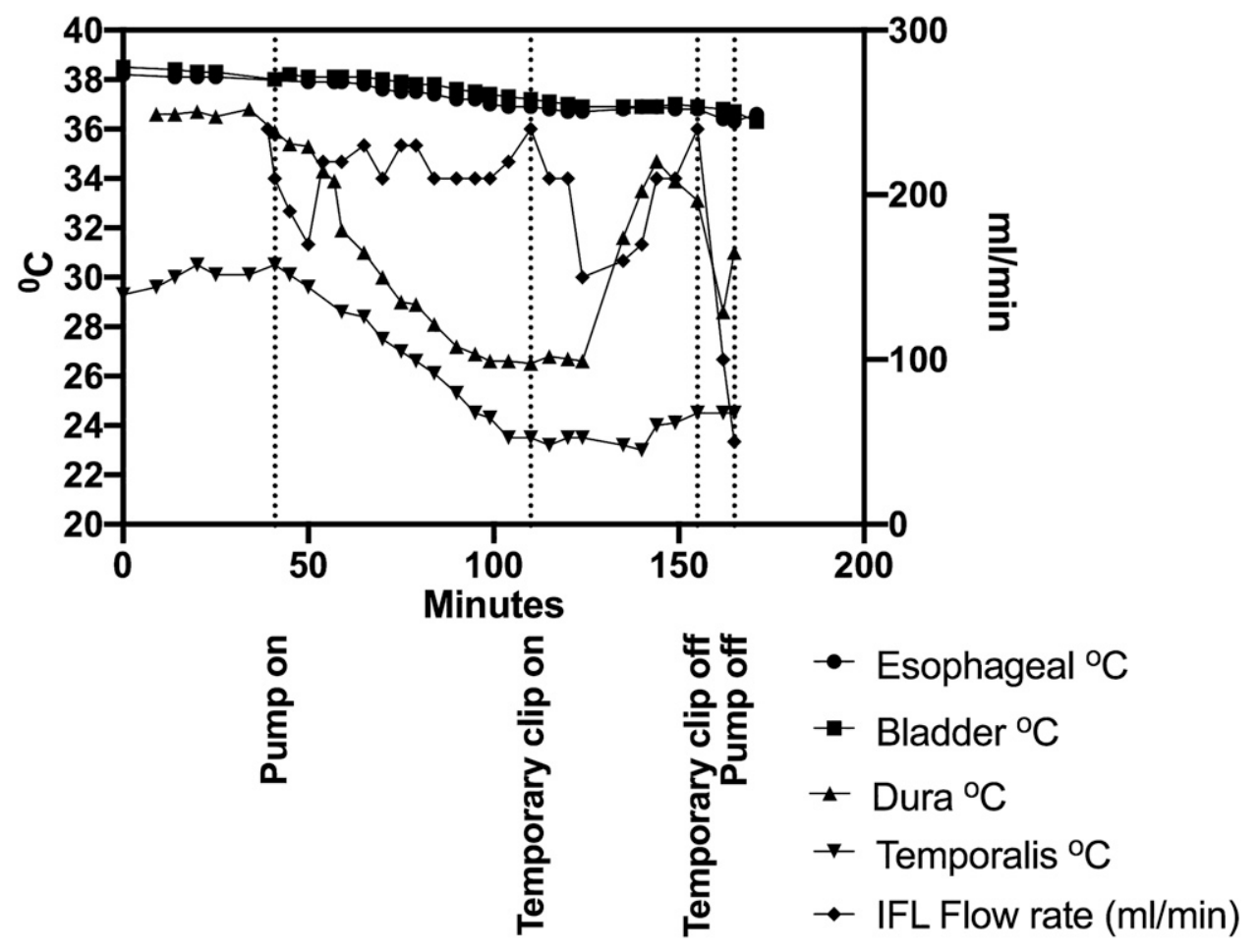

FIG. 2. Graphical demonstration of the four temperatures against the cold blood infusion rate. The two core temperatures remain relatively constant, while the cranial temperatures drop. There is an increase in subdural temperature when the flow rate decreases during aneurysm trapping, which was then corrected by increasing flow rates.

consequences of arrhythmias and coagulopathy, was first described in the 1950s. ${ }^{10}$ Initially disappointing results in animal models were followed by success..$^{11}$ Subsequently, selective hypothermia was used in 10 patients during the 1960s. However, supranormal perfusion pressures thought to be necessary to achieve global cerebral cooling probably contributed to poor outcomes. ${ }^{12}$ Resurgent interest in this method of neuroprotection using single carotid hypothermic perfusion successfully achieved brain cooling in baboons with only mild systemic cooling and demonstrated stroke volume reduction. ${ }^{13,14}$

In 2004, the Western University group used selective hypothermia for thrombectomy and clip reconstruction of a giant partially thrombosed right MCA aneurysm without full cardiac arrest. ${ }^{6}$ Using largebore cannulas to establish a circuit from the femoral artery to the CCA, cardiopulmonary extracorporeal circulation transferred oxygenated cooled arterial blood to the affected hemisphere. This technique achieved a brain temperature of $22^{\circ} \mathrm{C}$ for 20 minutes of complete MCA trapping with a cardiopulmonary perfusion time of 54 minutes. By comparison, the 2 largest series of deep hypothermic cardiac arrest had full cardiopulmonary bypass times of 95 and 132 minutes, respectively, resulting in mean body temperatures of $15^{\circ} \mathrm{C}$ and $17.6^{\circ} \mathrm{C}$ with mean circulatory arrest times of 22.9 and 26.2 minutes..$^{4,5}$ In the present case, with use of an entirely percutaneous circuit, selective perfusion time was 124 minutes with aneurysm trapping time of 29 minutes and a brain temperature nadir of $26.5^{\circ} \mathrm{C}$.

\section{Observations}

Endovascular delivery is a logical next step in the development of selective hypothermia for aneurysm treatment. The team's extensive experience (including the perfusionist and anesthesiologist) with the TwinFlo device was obtained through a preceding series of largeanimal experiments. ${ }^{7}$ For this case, the setup time was 40 minutes from placing the OFL in the descending aorta to the start of perfusion. The temperature descent to $26.5^{\circ} \mathrm{C}$ over 71 minutes was intentional to avoid overperfusion, because this has been suggested to contribute to morbidity. ${ }^{6,12}$ On the basis of prior experience, the initial flow rate of 240 $\mathrm{mL} / \mathrm{min}$ was reduced to $170 \mathrm{~mL} / \mathrm{min}$ while the chiller temperature was reduced from $25^{\circ} \mathrm{C}$ to $5^{\circ} \mathrm{C}$. The subdural temperature decreased to $30^{\circ} \mathrm{C}$ in about 30 minutes, consistent with prior experience in the porcine model. The aneurysm was thrombectomized once the temperature dropped to $26^{\circ} \mathrm{C}$. The IFL balloon catheter pressure transducer demonstrated ICA pressures of 65 to $85 \mathrm{~mm} \mathrm{Hg}$, slightly below and correlating well with peripheral mean arterial pressures. Once selective perfusion was established, reductions in flow rate to $<200$ $\mathrm{mL} / \mathrm{min}$ for 20 minutes during aneurysm trapping resulted in subdural temperature increasing $8^{\circ} \mathrm{C}$. Temperature decreased again as the flow rate was increased above $200 \mathrm{~mL} / \mathrm{min}$. Thus, flow rate in a cold blood perfusion model drives the temperature once the inflow temperature is fixed. This is similar to previous experience. ${ }^{6}$ Unlike whole-body deep hypothermic circulatory arrest, perfusion to the hemisphere is never interrupted in selective hypothermia.

Another technical consideration is the level of arterial occlusion. The inflow balloon catheter placed in the CCA allows extracranial muscle and dura via the external carotid artery, in addition to leptomeningeal flow from the anterior cerebral artery, to provide additional cooling to the affected hemisphere even during aneurysm trapping. In this patient, the temporalis muscle measured $5^{\circ} \mathrm{C}$ lower at baseline 
than the subdural probe. The target brain temperature of $26^{\circ} \mathrm{C}$ was thus based on subdural probe readings. The temporalis muscle dropped to $23^{\circ} \mathrm{C}$ but did not show sensitivity to flow rates. This may be due to decreased temporalis perfusion from retraction but suggests that the temporalis muscle temperature is probably not reliable.

Hypothermia has 2 significant side effects that are handled differently by a selective approach: cardiac arrhythmias and coagulopathy. Deep hypothermic cardiac arrest addresses arrhythmias by placing the patient on cardiopulmonary bypass, with the corresponding risks. Selective hypothermia avoids this altogether because core temperatures routinely stay above $34^{\circ} \mathrm{C}$. In both this case and a previous selective brain cooling report, core temperatures never dropped below $34^{\circ} \mathrm{C}$. The second side effect, coagulopathy, can be profound. ${ }^{8}$ Postoperative hemorrhage is a known complication of deep hypothermic circulatory arrest due to a combination of temperatureassociated coagulopathy and the bypass circuit elements depleting clotting factors. ${ }^{4,5,9}$ Selective hypothermia requires significant heparinization but can be monitored with ACT. Nonspecific coagulopathy seen with systemic hypothermia has not been encountered.

Arguments against the use of hypothermia for aneurysm treatment have been made on the basis of high morbidity and mortality in deep hypothermic arrest and advancements of endovascular technology. An endovascular solution could have very effectively treated this lesion. However, we believe there is a still a role for surgical clip ligation in the treatment of giant partially thrombosed aneurysms at bifurcations even in the anterior circulation. ${ }^{5}$

\section{Lessons}

Selective hypothermia efficiently cools the brain while avoiding the complications of systemic hypothermia. We present the evolution of the method to an entirely endovascular system, with results similar to both extensive animal laboratory data and a single modern case of open selective hypothermia. Selective brain cooling to $26^{\circ} \mathrm{C}$ represents a significant decrease in cerebral metabolic rate of oxygen, allowing prolonged ischemia times for thrombectomy and clip reconstruction in partially thrombosed giant aneurysms. Further research into this technique is appropriate.

\section{Acknowledgments}

Ron Solar, PhD, and Glen Lieber of Thermopeutix, Inc., are acknowledged for supplying the catheter and some data collection.

\section{References}

1. Botterell EH, Lougheed WM, Scott JW, et al. Hypothermia, and interruption of carotid, or carotid and vertebral circulation, in the surgical management of intracranial aneurysms. J Neurosurg. 1956;13(1):1-42.

2. Lawton MT, Spetzler RF. Surgical management of giant intracranial aneurysms: experience with 171 patients. Clin Neurosurg. 1995;42(1):245-266.

3. Connolly ES Jr, Solomon RA. Hypothermic cardiac standstill for cerebral aneurysm surgery. Neurosurg Clin N Am. 1998;9(4): 681-695.

4. Mack WJ, Ducruet AF, Angevine PD, et al. Deep hypothermic circulatory arrest for complex cerebral aneurysms: lessons learned. Neurosurgery. 2007;60(5):815-827.
5. Lawton MT, Raudzens PA, Zabramski JM, et al. Hypothermic circulatory arrest in neurovascular surgery: evolving indications and predictors of patient outcome. Neurosurgery. 1998;43(1):10-21.

6. Lownie SP, Menkis AH, Craen RA, et al. Extracorporeal femoral to carotid artery perfusion in selective brain cooling for a giant aneurysm. Case report. J Neurosurg. 2004;100(2):343-347.

7. Mattingly TK, Denning LM, Siroen KL, et al. Catheter based selective hypothermia reduces stroke volume during focal cerebral ischemia in swine. J Neurointerv Surg. 2016;8(4):418-422.

8. Drake CG, Barr HW, Coles JC, et al. The use of extracorporeal circulation and profound hypothermia in the treatment of ruptured intracranial aneurysm. J Neurosurg. 1964;21(7):575-581.

9. Solomon RA, Smith CR, Raps EC, et al. Deep hypothermic circulatory arrest for the management of complex anterior and posterior circulation aneurysms. Neurosurgery. 1991;29(5): 732-738.

10. Lougheed WM, Kahn DS. Circumvention of anoxia during arrest of cerebral circulation for intracranial surgery. J Neurosurg. 1955; 12(3):226-239.

11. Verdura J, White RJ, Albin MS. Profound selective hypothermia and arrest of arterial circulation to the dog brain. J Neurosurg. 1966; 24(6):1002-1006.

12. Williams BN, Turner EA. Report of 10 operations under local cerebral hypothermia. J Neurol Neurosurg Psychiatry. 1970;33(5): 647-655.

13. Schwartz AE, Stone JG, Finck AD, et al. Isolated cerebral hypothermia by single carotid artery perfusion of extracorporeally cooled blood in baboons. Neurosurgery. 1996;39(3):577-582.

14. Schwartz AE, Finck AD, Stone JG, et al. Delayed selective cerebral hypothermia decreases infarct volume after reperfused stroke in baboons. J Neurosurg Anesthesiol. 2011;23(2): 124-130.

\section{Disclosures}

The authors report no conflict of interest concerning the materials or methods used in this study or the findings specified in this paper.

\section{Author Contributions}

Conception and design: Mattingly, Lopez-Ojeda, Kakani, Lehrbass, Lownie. Acquisition of data: Lopez-Ojeda, Arango, Lehrbass, Lownie. Analysis and interpretation of data: Mattingly, Lownie. Drafting the article: Mattingly. Critically revising the article: Mattingly, Arango, Lownie. Reviewed submitted version of manuscript: Mattingly, Arango, Harle, Lownie. Approved the final version of the manuscript on behalf of all authors: Mattingly. Administrative/technical/material support: Lopez-Ojeda, Harle, Allen, Lehrbass, Lownie. Study supervision: Lownie. Surgical setup assistance: Lehrbass. Radiologic imaging: Lehrbass.

\section{Supplemental Information}

Previous Presentations

Portions of this work were presented in electronic poster form at the American Association of Neurological Surgeons Annual Meeting, Chicago, IL, April 30 to May 4, 2016.

\section{Correspondence}

Thomas K. Mattingly: University of Rochester, Rochester, NY. thomas_mattingly@urmc.rochester.edu. 